\title{
TEACHING OF BEHAVIORAL AND EXPERIMENTAL ECONOMICS AND THE PROSPECTS FOR TEACHING IT IN DEVELOPING COUNTRIES: A SURVEY
}

\author{
Muhammad Ryan Sanjaya \\ Universitas Gadjah Mada \\ (m.ryan.sanjaya@ugm.ac.id)
}

\begin{abstract}
The rising trend of behavioral and experimental economics is observed through a survey of the top 100 academic institutions in economics and econometrics. The survey found that this subject is relatively popular with around $44 \%$ of academic institutions offering this course to undergraduate students. Another survey on publication interest found a surge since 2002 that was experienced by this subject along with only a few other subjects such as labor economics and business economics. Lastly, four short experiments on undergraduate students were conducted in Indonesia to explain economics, and this activity seems to support the studentcentered learning that has since became the focus of the Directorate General of Higher Education in Indonesia.
\end{abstract}

Keywords: behavioral and experimental economics, economics teaching, developing countries

JEL codes: A12, A22, D03

\section{INTRODUCTION}

Economics and psychology has intertwined since Adam Smith published his Theory of Moral Sentiments and David Hume's discussion on the importance of non-economic factors in economic decision making (Smith, 2010; Hume, 1739, 1875). The study on economic psychology, sometimes labelled as behavioral economics, has emerged ever since and there has been an evolution from the "Old Behavioral Economics" to the "New Behavioral Economics” (Sent, 2004; Hosseini, 2011). The difference between the 2 mainly lies in how the former departs from finding an alternative to the mainstream economics and draws insights from the vast literatures on psychology, while the latter is less punitive and has found ways to embrace psychological concepts into mainstream economic models (Sent, 2004).

The current teaching of behavioral economics now mostly follows the "New Behavioral Economics" path that acknowledges a human's limited cognitive ability (bounded rationality), preference over the status quo, and loss aversion (Gigerenzer \& Selten, 2002; Samuelson \&
Zeckhauser, 1988; Kahneman et al., 1991; Kahneman \& Tversky, 1984). The emerging interest in behavioral economics is also followed by the increasing use of (laboratory) experiments that can help explain the limited psychological foundations of mainstream economics and, consequently, help contribute to the body of knowledge of behavioral economics.

While behavioral economics has now been accepted by many economics departments in industrialized economies, the prospects for teaching this subject in developing countries remains in question. The originality of this study is therefore based on 2 activities: first, a bird's eye view of the teaching of (undergraduate) behavioral economics in the top 100 academic institutions for economics and econometrics, collecting information on the general requirements for the study, and how academic publications on behavioral economics evolve over time. Second, this study observed the current curriculum and teaching of economics in academic institutions in several developing economies and offers an example of the teaching of behavioral/experi- 
mental economics to undergraduate economics students in Indonesia.

Early findings from this study show that behavioral economics is increasingly more popular in terms of the number of publications on this subject and is being embraced by top academic institutions. The author also found that undergraduate students in Indonesia, a developing country, are content with class experiments on behavioral economics and therefore, universities in developing countries should be encouraged to introduce this subject at undergraduate level. Therefore, this study gives a contribution to the literature on economic's education, with particular interest given to the prospect of teaching behavioral economics in developing countries.

\section{UNDERGRADUATE BEHAVIORAL ECONOMICS IN TOP UNIVERSITIES: A SURVEY}

A simple survey of the behavioral economics curriculum was conducted by browsing through the top 100 academic institutions for economics and econometrics as published by QS in 2013. ${ }^{1}$ Since only the top 100 academic institutions were surveyed, the results cannot be generalized to the general economics department. From a sample of 100 academic institutions, only 92 are included in this study due to the unavailability of online curricula and courses offered by 8 academic institutions' websites.
Various names have been assigned to describe this course-such as "Behavioral Economics: Theory and Applications" (University of Glasgow), "Experimental and Behavioral Economics" (Tilburg University), and "Behavioral Finance and Economics" (Princeton University)—but "Behavioral Economics" is the most popular one with 22 out of 40 academic institutions using this name.

Data from the survey shows that there is a large interest in behavioral economics as indicated by the fact that 40 (44\%) of 92 academic institutions surveyed offer this course at undergraduate level. It was found that most of these 40 academic institutions are located in North America (see Figure 1), particularly in the United States (18 academic institutions), followed by Australia (6), the Netherlands (4) and the United Kingdom (4).

The survey also found that behavioral economics is usually taught as an elective for $2^{\text {nd }}$ and $3^{\text {rd }}$ year students who already took an intermediate course on microeconomics. ${ }^{2}$ This indicated support for the claim that the "New Behavioral Economics" is not going to replace mainstream/neoclassical economics but "may help rebuild the mainstream stronghold” (Sent, 2004).

\section{Publication interest in behavioral economics}

The rise of the teaching of behavioral economics is also followed by an increasing number

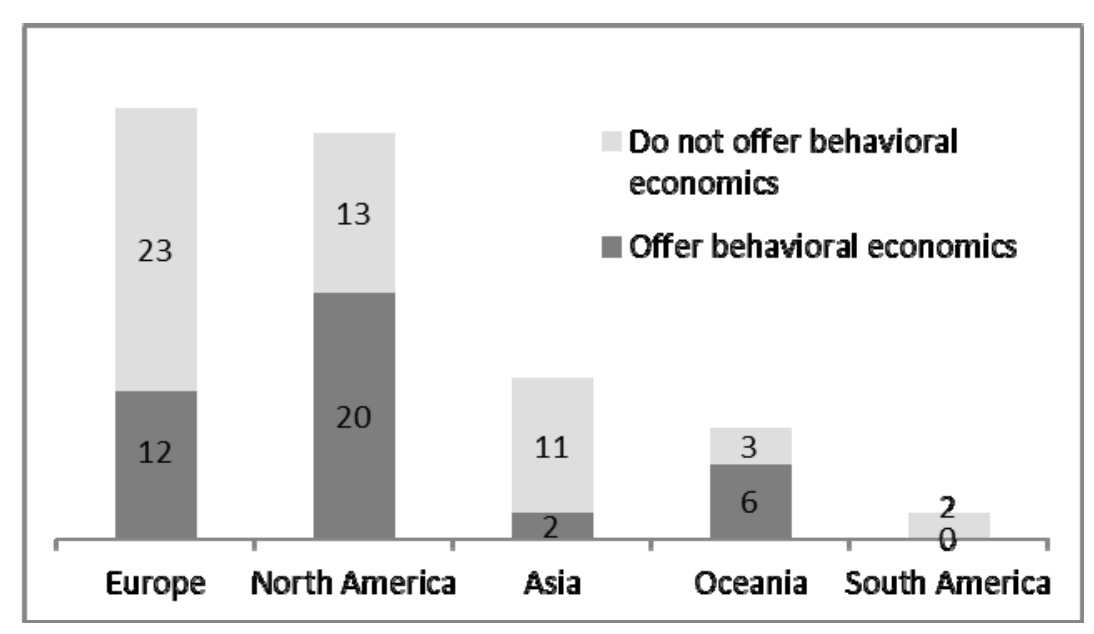

Source: processed from various academic institutions’ websites

Figure 1: Universities offering behavioral economics courses 
of publications related to this subject. A survey of publications on this subject from ScienceDirect - one of the largest scientific databases that provides the academic publication of more than 2,500 peer-reviewed journals and more than 11,000 books - was conducted with a time frame from 1961 to 2014 . $^{3}$ The survey found that publications on behavioral economics gained significant momentum from early 2000, possibly due to Daniel Kahneman's and Vernon L. Smith's Nobel Memorial Prize in Economic Sciences in 2002, that might have contributed to the increasing popularity of this subject.

Comparing behavioral economics with other research topics in economics produced some interesting results. Firstly, as Figure $2 \mathrm{~b}$ suggests, it seems that publications on traditional research topics such as monetary economics, international economics, public economics, and development economics exhibit a similar pattern where they grew quickly between the 1970s to the late 1990s, but then experienced a large drop around 1998, which coincided with the Asian Financial Crisis. Up until this article was written, the number of publications in those fields have never reached the same level as their peak in 1995-1996.

Secondly, as mentioned earlier, publications on behavioral and experimental economics have gained momentum since 2002 and do not show any signs of contracting yet (a similar thing also occurred for publications on experimental economics which have a large correlation with the number publication in behavioral economics). In fact, it seems that the onset of the Asian Financial Crisis triggered a rising tide of publications on behavioral and experimental economics (see Sanjaya (2013), for example, for an elaboration of this matter). It also needs to be noted that besides these 2 fields, labor economics and business economics also exhibit a similar trend despite the fact that the popularity of the latter research topics dropped quite a lot around 19971998. See Figure 2a above.

In this section it can be found that behavioral economics is increasingly accepted in mainstream economics as shown by the large proportion of academic institutions that embrace this subject in their curricula and by the rising amount of academic publications on the subject. The next section will observe how the current teaching of economics in developing countries, with respect to behavioral economics, is progressing and provide an example of practicing behavioral/experimental research in Indonesia.

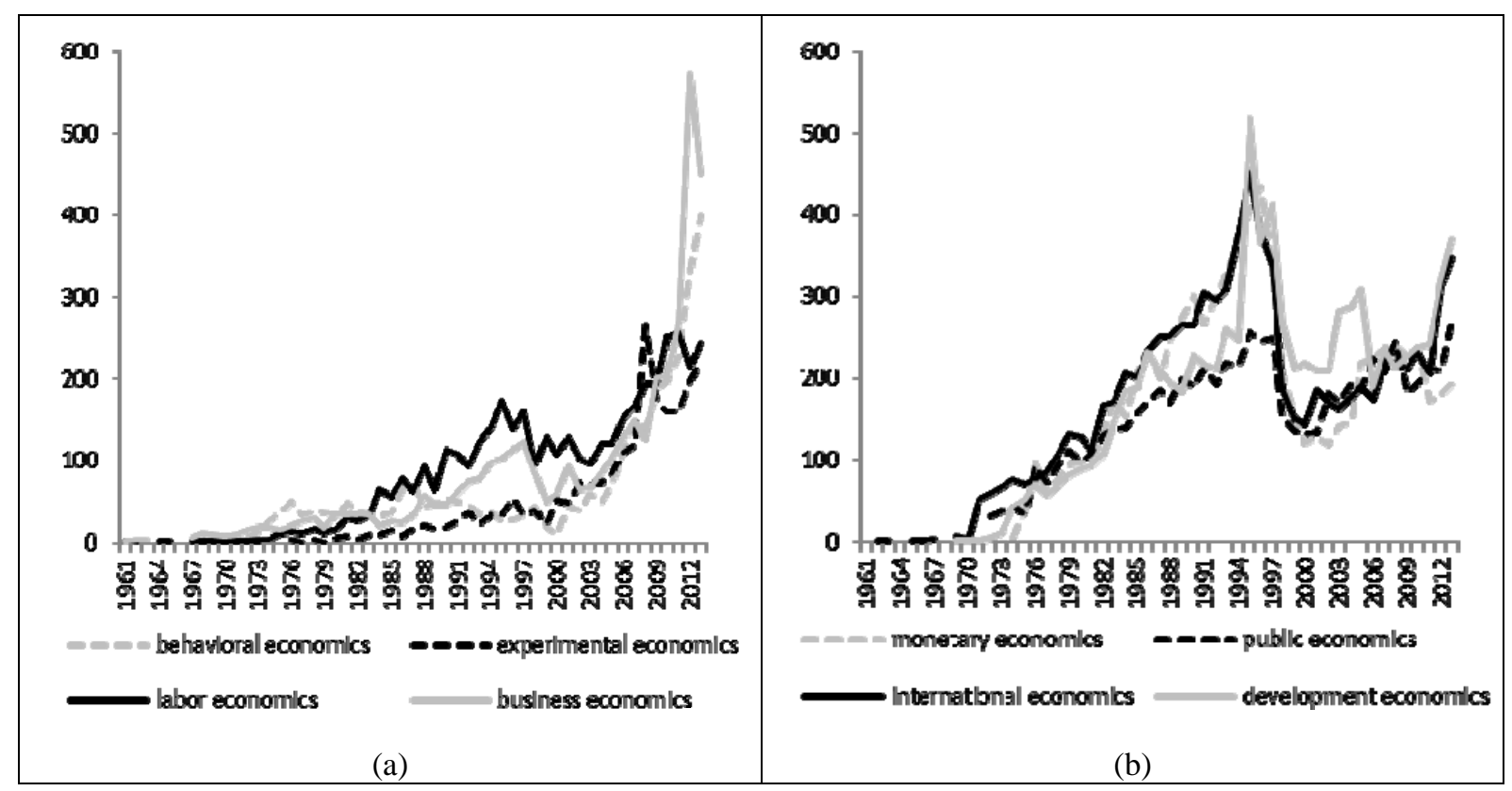

Source: processed from ScienceDirect

Figure 2: Publications in behavioral economics and other topics in economics 


\section{TEACHING OF (BEHAVIORAL) ECONOMICS IN DEVELOPING COUNTRIES}

The first part in the previous section shows the distribution of academic institutions that offer behavioral economics as one of the electives at undergraduate level from a sample of 92 top campuses for economics and econometrics (Figure 1). The figure, however, is biased toward developed countries since nearly all the academic institutions in the top 100 are from these industrialized economies. ${ }^{4}$ Therefore, a discussion on the teaching of economics, with particular attention given to the teaching of behavioral economics, in developing countries is delivered in this section.

The first barrier of teaching (behavioral) economics in developing countries is the fact that the majority of the population living in developing countries does not use English as their main language. While this is a common problem with teaching economics, that mainly uses western (English language) academic materials, but this issue becomes even more challenging because of the emergence of behavioral economics (compared to the standard micro- and macroeco- nomics) which provides relatively few teaching/textbook materials.

Other than the language issue, it is standard to study economics using a mathematical approach today, an approach in which many developing countries fare poorly. Using data from the 2012 Program for International Student Assessment (PISA), which assessed the skills and knowledge of students aged 15 years in 65 countries, there is a clear positive correlation between mathematical performance and GNI per capita, using the Atlas method (in current US\$) (see Figure 3). ${ }^{5}$ In fact, the average mean score in mathematics in low and middle-income countries (426) is significantly lower than in highincome countries (494). Combined with language problems, this lack of mathematical skill could have the potential to hamper the development of the study of economics at universities in developing countries.

Apart from these language and mathematical barriers faced by academic institutions in developing countries, it was found that there are only 2 universities (out of 11 academic institutions from developing countries in the top 200 academic institutions) that provide a behavioral

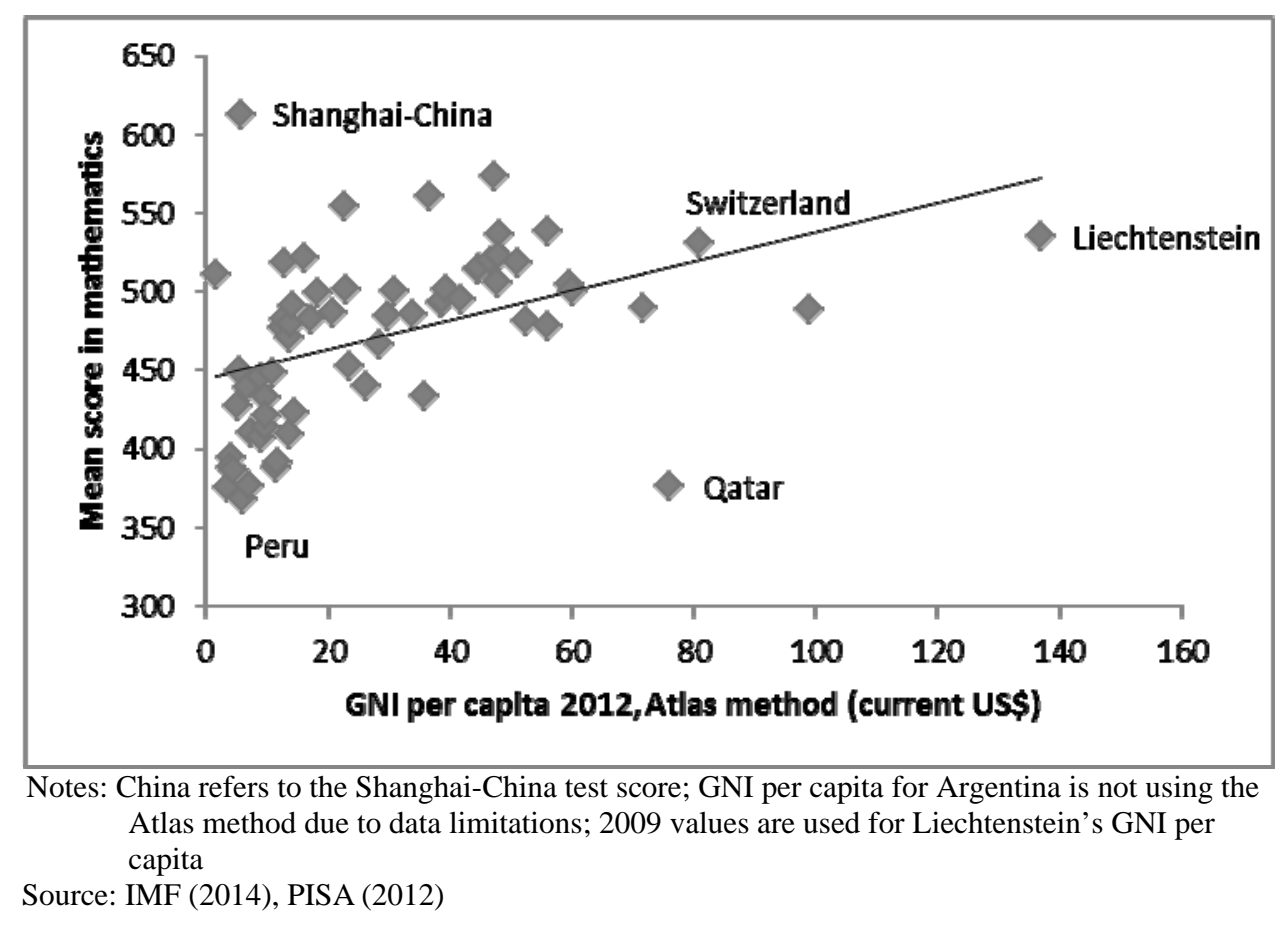

Figure 3: GDP per capita (in PPP dollar) and PISA 2012 mathematical performance 
economics course at undergraduate level (University of Cape Town in South Africa and Renmin University of China). ${ }^{6}$ One interesting fact from the teaching of the "Views of Institutional \& Behavioral Economics" course offered at the University of Cape Town is that it required higher level pre-requisites compared to those required in academic institutions for advanced economies. ${ }^{7}$ This gives an early indication that, unlike their counterparts in advanced economies, sophomore undergraduate students in developing economics are assumed to be relatively unprepared to deal with behavioral issues. ${ }^{8}$

\section{Institutional arrangements for developing curriculum and teaching in Indonesia}

This paper's focus on the prospects for teaching behavioral economics in developing countries is concentrated on the case of Indonesia. As a part of the G20, Indonesia lacks in many socio-economic aspects of (higher) education. For example, the average gross enrolment ratio for tertiary education from 2002-2011 was just 23.1\%, almost 50\% smaller than Malaysia - a neighbor of Indonesia and also a developing country - which had 40.2 percent over the same period. Nonetheless, there is a great demand for education in Indonesia since the country is committed to the ASEAN Economic Community in 2015, which envisages the free mobility of skilled labor.

The development of higher education curriculum in Indonesia is regulated by the Law 12/2012 on Higher Education that urged the need to have higher education curricula that are based on competency as defined in Government Regulation 17/2010 and Presidential Regulation 8/2012. Government Regulation 19/2005, in particular, provides great flexibility for higher education institutions to develop their own curricula as long as they are following the national qualification framework that refers to the competency of the graduated students.

According to the Handbook of Competencebased Curriculum Development for Higher Education published by the Directorate General of Higher Education, the development of a new subject (such as Behavioral Economics) must be based on: 1) a scientific vision of the program study, and; 2) a need assessment (market signal). As described in the previous section, the growing number of academic institutions offering behavioral economics clearly signals the demand for such a subject.

In the same handbook, there is also the need to move from teacher-centered learning (TCL) to student-centered learning (SCL) that emphasizes the importance of student-lecturer interaction in the class. The frequent use of experimental methods to understand behavioral economics where the students are directly involved in the experiment obviously supports SCL.

\section{Experimenting experimental and behavioral economics in Indonesia: some trials}

Acknowledging the importance of introducing behavioral and experimental economics, 4 experiments on microeconomic theory and behavioral economics were performed in several undergraduate classes. Below is the summary of these experiments.

\section{Leveraged asset experiment}

First, a laboratory experiment on asset price was conducted with 18 Microeconomics II students who should have already been familiar with basic calculus and the time value of money concept. The experiment used Veconlab's (http://veconlab.econ.virginia.edu/admin.htm) built-in Leveraged Asset Market experiment where students may trade asset(s) that they have, where each asset preserved will have a dividend in return. ${ }^{9}$ There were 20 rounds in the experiment, where each subject received 6 units of assets and $\$ 10$ cash at the beginning of the experiment. The subject also received an additional \$US 10 income in each round and all the cash they managed to keep generated an income (interest). It was also possible to borrow money to buy assets as long as the subject had sufficient cash in hand.

The experiments showed a price escalation and the market-clearing price exceeded the fundamental value of the asset by round 9. The price continued to go up and reached its peak in round 16. The price fell quickly in the last 4 
rounds after the subjects realized that "the party cannot last all night”. The final market-clearing price in round 20 was \$US 28 (which is equal to the fundamental value of the asset). See Figure 4 below.

The experiment demonstrated the herd behavior of economic agents and how price bubbles are formed due to expectations of price increases. This experiment is a nice example of how "animal spirit" is experienced directly by the students and how their behavior deviates from the standard predictions of rational, farlooking, economic agents. It is also relevant when combined with a lecture on the recent financial crisis, or on any crisis that was caused by price bubbles. ${ }^{10}$

Nonetheless, the above result is subject to the number of participants in the experiment. It was repeated with the same settings but with many fewer subjects (only 4 students), and the result showed no price escalation and the market-clearing price was far below the predicted fundamental value. This could be explained by: 1) the number of players in this experiment was too few to form the herd behavior amongst themselves; 2) risk aversion, and; 3) confusion in understanding the instructions.

\section{Auction experiment}

The second experiment was a first-price auction (FPA) and second-price auction (SPA) using, again, Veconlab's experiment design.
Compared to the previous experiment on a leveraged asset market, this experiment is much simpler and a nice companion to the study of auction theory that is usually taught in advanced microeconomic theory.

There were 23 participants in both experiments where each participant was matched with the same person in the whole 20 rounds (10 rounds for the FPA experiment and another 10 for the SPA experiment). Each participant received a unique and randomly drawn prize values for the item being auctioned in each round. In every round, the participants may submit a bid but they cannot observe other participants' prize values or bids. The results of the experiment are given in figure 5 below.

Standard microeconomic theory suggests that the optimal bidding behavior in an FPA is to bid below the private value, while in a SPA it is best to bid equal to the private valuation of the goods being auctioned. As can be seen from above figure, the results from FPA and SPA experiment are relatively close to those predicted by the theory.

It is interesting also that there is an indication that the subjects of the experiments are willing to receive a "winner's curse" since the experiment do not use real money. This is because there were a lot of subjects that were willing to pay nearly twice their private value which drove the bid/value ratio to be around 1.7 in the first 3 rounds of the SPA experiment.

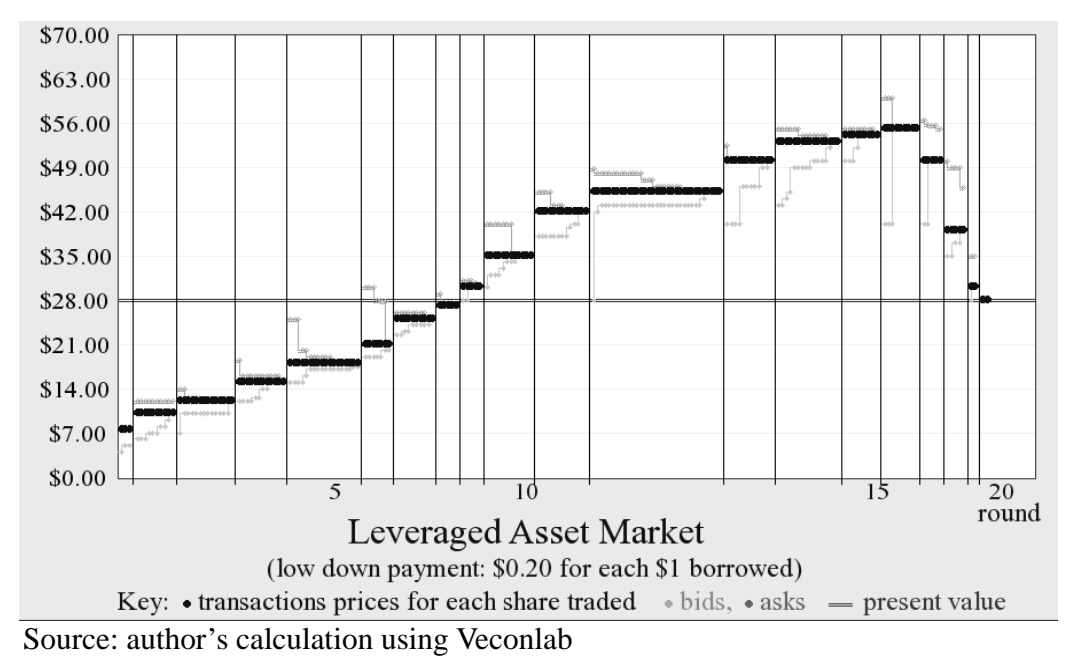

Figure 4: Price escalation in a leveraged asset market experiment 


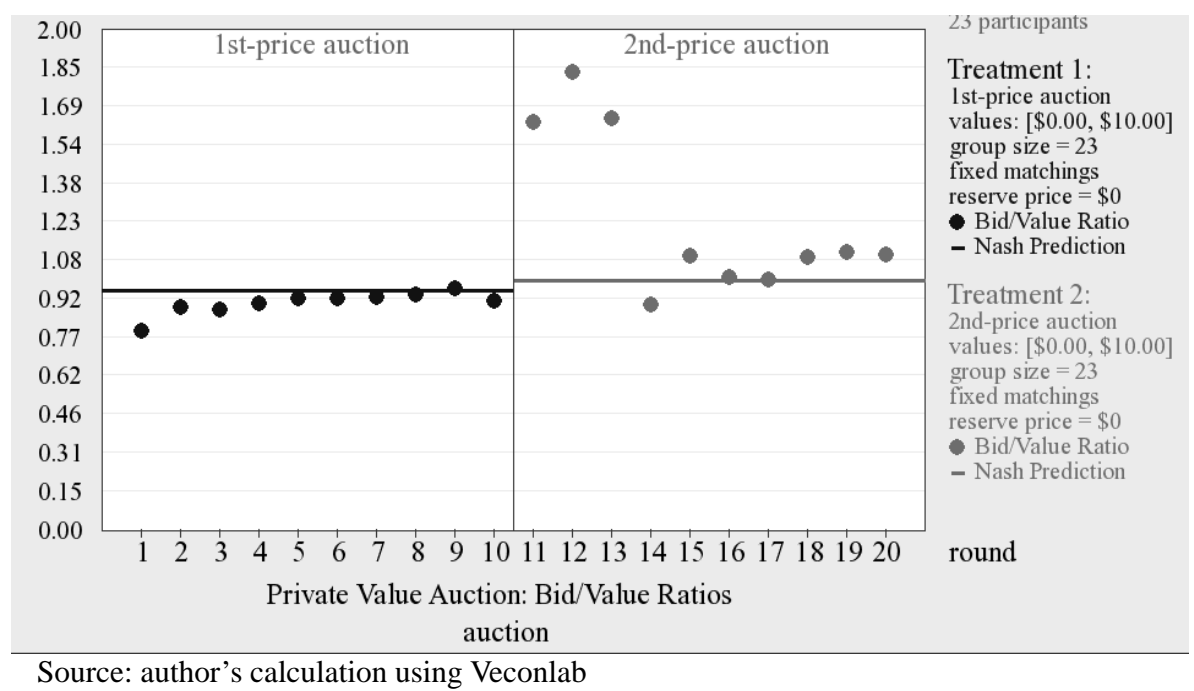

Figure 5: Private value auction experiment

Once the instructor made an additional rule saying that those who pay more than their private valuation of the goods must pay (in cash) the difference, the average bid/value ratio dropped and hovered around the predicted ratio (bid/value = 1).

\section{St. Petersburg experiment}

The third experiment discussed is the St. Petersburg experiment. This experiment does not need any sophisticated tools such as computers (as needed in the previous two experiments) and only needs the basic pen-and-paper. The experiment started by asking how much the participant was willing to pay to engage in a bet like this:

"How many flips of a coin are needed before it ends up heads (or tails)? If heads come up on the $m^{\text {th }}$ toss, then the participant receives $2^{m}$."

The subjects in this experiment were 36 undergraduate students in the Microeconomic II class. While the average amount they were willing to pay was \$US 41, but 31 of them (86\% of the sample) were only willing to pay less than or equal to \$US 16. This result is in line with numerous St. Petersburg experiments that have been done in many places and demonstrates the violation of the predicted infinite willingness-topay (or infinite expected value of the bet) to participate in this gamble very well. This experiment is relevant in the teaching of behavioral economics because several studies claim that loss-aversion can help explain the paradox in this experiment (Camerer, 2005).

\section{Schelling segregation exercise}

The final experiment discussed here nicely describes the myopic behavior of economic agents. This "experiment" is actually an exercise or a demonstration of the segregation theory proposed by Schelling (1978). This exercise only required a sticker (a "post-it” would serve better) and a matrix drawn on a whiteboard. Differing from the previous 3 experiments, this exercise does not require very active participation by the students and their role is only limited to suggesting a move during the experiment.

The experiment begins by setting the environment such as the size of the matrix, the type of "individuals" living in a "neighborhood", and the preference of the "individuals". For example, there are 50 individuals that consist of 2 types, blacks and reds, who live in a 10x10 matrix/ neighborhood. The preference given is that blacks (reds) are only willing to tolerate at most 2 reds (blacks) in their direct neighborhood. If a black (red) lives with more than two reds (blacks), then this particular black must move to the nearest available cell that satisfies the preference, and so on and so forth. This process may quickly end with a few movements or it may continue to go on and result in a segregated 
neighborhood. In fact, under certain setting, it can be shown during the experiment that segregation may occur even when there is a low aversion to mixing among the individuals. Therefore, this exercise may have multiple equilibria, either stable or unstable equilibria.

\section{Perception and expectation of the teaching of undergraduate behavioral economics}

Students participating in the above experiments were asked (voluntarily) to fill in a short online survey on their perceptions and expectations of the teaching of undergraduate behavioral economics. From the 23 students who filled in the survey, all of them (100\%) agree or very agree that behavioral and experimental economics is important and needs to be introduced at undergraduate level in Indonesia. Around 58\% said that they got more understanding on the limits of economic theories, while $38 \%$ said that they became more certain of its strengths, and just 1 person that said that he/she got nothing from the experiment. The majority (65\%) also stated that they prefer laboratory experiments to field surveys (30\%) or student presentations (4\%) as an addition to traditional (one-directional) lectures.

Figure 6 above shows the likeliness of introducing behavioral and experimental economics at undergraduate level in Indonesia. About 74\% said that it is likely to be introduced as a subject in 1-2 years, despite some respondents (13\%) that said that it is unlikely to be in the near future. A more realistic time to introduce this subject would be in the next 3-4 years where all the respondents said that it is likely or very likely. About $82 \%$ also said that it is unlikely or very unlikely to not having this subject introduced at the undergraduate economics level in Indonesia.

Nonetheless, the respondents also realized that various limitations could hamper the introduction of this new subject and they pointed out that the main obstacle would be on the availability of teaching staff $(29 \%)$ and the fact that the material will be harder than standard economics theories (29\%). It is also interesting to know that the respondents felt that the student's enthusiasm would not be a problem since only $6 \%$ of them that said that it would be.

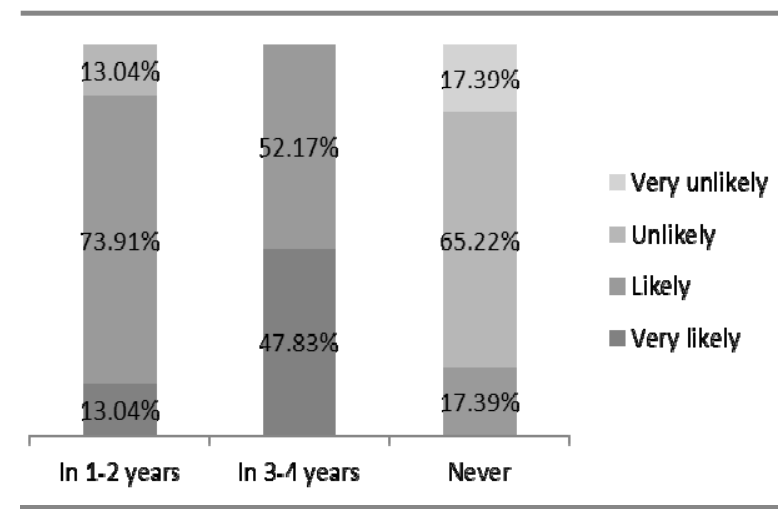

Source: author's calculation

Figure 6: The likeliness of introducing undergraduate behavioral and experimental economics in Indonesia

\section{CONCLUSION}

The popularity of behavioral and experimental economics since the early 1990s has led to numerous academic publications and has been offered in many undergraduate classes, mostly in the US. The surge in publications since the early 2000s is probably due to the Nobel Prize in economics that was awarded to Daniel Kahneman in 2002 and also due to the Asian Crisis that gave rise to questions about the validity of mainstream economic teaching at that time. It should be noted, however, that even though some academic institutions do not offer the subject at undergraduate level, it does not necessarily means that it is not offered at the graduate level.

Finally, the short exploratory work of the 4 simple experiments that were conducted to explain some of the teaching materials/methods to undergraduate students in Indonesia seemed to be relevant to the student-centered learning that has been one of the focuses of the Ministry of Education through its Directorate General of Higher Education. A short survey of the participants of the laboratory experiments was also supportive of the idea that undergraduate behavioral and experimental economics is important and should be introduced soon. Acknowledging the rising interest in behavioral and experimental economics, and the fact that it could help students to understand the teaching materials better, 
teaching in this subject should be encouraged and formally added to the current curricula of economics in developing countries, particularly Indonesia.

\section{REFERENCES}

Camerer, C., 2005. "Three cheers-psychological, theoretical, empirical-for lossaversion”. Journal of Marketing Research, 42 (2): 129-133.

Gigerenzer, G. and S. Reinhard, 2002. Bounded Rationality: The Adaptive Toolbox. MIT Press. ISBN 0-262-57164-1.

Hosseini, H., 2011. "George Katona: A founding father of old behavioral economics," Journal of Behavioral and Experimental Economics, 40 (6): 977-984.

Hume, D., 1739. A Treatise on Human Nature, ed. L. A. Selby-Bigge and P. H. Nidditch. Oxford: Clarendon Press.

Hume, D., 1875. The Philosophical Works of David Hume, ed. T. H. Green and T. H. Grose. London: Longman, Green.

IMF, 2014. World Economic and Financial Surveys - World Economic Outlook (WEO). URL: http://www.imf.org/external/Pubs/ft/ weo/2014/01/

Kahneman, D. and A. Tversky, 1984. "Choices, Values, and Frames”. American Psychologist, 39 (4): 341-350.

Kahneman, D., J. L. Knetsch, R. H. Thaler, 1991. "Anomalies: The Endowment Effect, Loss Aversion, and Status Quo Bias”. Journal of Economic Perspectives, 5 (1): 193-206.

PISA, 2012. Programme for International Student Assessment (PISA) - 2012 Results. URL: http://www.oecd.org/pisa/keyfindings/ pisa-2012-results.htm

QS, 2013. QS World University Rankings by Subject 2013 - Economics \& Econometrics. URL: http://www.topuniversities.com/ university-rankings/university-subjectrankings/2013/economics-and-econometrics
Samuelson, W. and R. Zeckhauser, 1988. "Status quo bias in decision making”. Journal of Risk and Uncertainty, 1: 7-59.

Sanjaya, M. R., 2013. "Mea Culpa, Economica: Perkembangan Konsep dan Pengajaran Ilmu Ekonomi Pasca Krisis Ekonomi Global 2008”. Gadjah Mada Working Paper in Business \& Economics.

Schelling, T. C., 1978. Micromotives and Macrobehavior. W.W. Norton.

Sent, E. M., 2004. "Behavioral Economics: How Psychology Made Its (Limited) Way Back Into Economics”. History of Political Economy, 36 (4)

Smith, A., 2010. The Theory of Moral Sentiments. Penguin.

\section{Websites}

Various university websites

ScienceDirect. URL: http://www.sciencedirect. com/

Veconlab - Experimental Economics Laboratory. URL: http://veconlab.econ.virginia.edu/

\section{Government regulations}

Law 12/2012 on Higher Education

Government Regulation 17/2010 on Education Management and Delivery

Government Regulation 19/2005 on National Education Standard

Presidential Regulation 8/2012 on National Qualification Framework.

\section{ENDNOTES}

1 See here for the complete list: http://www.topuniversities.com/universityrankings/university-subject-rankings/2013/economicsand-econometrics

2 While some academic institutions do not have prerequisite courses to be taken prior to taking behavioral economics, some others have strict prerequisites other than intermediate microeconomics (such as statistics and econometrics). But in general the prerequisite is intermediate microeconomics. 
3 The search is limited to "behavioral economics" (with quotation mark) to exclude other publications on behavior-related studies (such as cognitive psychology or consumer behavior). The search is also limited to full text rather than to all fields.

4 The exceptions are Fundacao Getulio Vargas and Universidade de Sao Paulo (Brazil); Pontificia Universidad Catolica de Chile (Chile); Peking University, Tsinghua University, Fudan University and Shanghai Jiao Tong University (China).

5 In fact, there is also a positive relationship between GNI per capita with reading skills and science skills.

6 Out of the top 200 universities surveyed by QS in 2013, there are only 11 academic institutions in developing countries that provide enough information on their websites about whether they offer a course on behavioral economics or not.

7 The prerequisites are Advanced Microeconomics plus Advanced Econometrics or equivalent or at the discretion of the Head of Department.
8 There is anecdotal evidence where a senior lecturer at a university in Indonesia insisted that behavioral economics shouldn't be taught at undergraduate level because it will "deconstruct" the whole basic-building of economic theories that could make the students confused.

9 The market-clearing price was obtained from a double auction mechanism.

10 Nonetheless, the above result is subject to the number of subjects who participate in the experiment. Another set up was made with the same setting but with fewer subjects (only 4 students) where the result shows no price escalation and the market-clearing price is far below the predicted fundamental value. This could be explained by: 1) the number of players in this experiment is too few to form a herd behavior among them; 2) risk aversion, and; 3) confusion in understanding the instructions. 